\title{
A Demand-Response Scheme Using Multi- Agent System for Smart DC Microgrid
}

\author{
Diana Severine Rwegasira, Royal Institute of Technology, Stockholm, Sweden \\ Imed Saad Ben Dhaou, Qassim University, Buraidah, Saudi Arabia \& University of Monastir, Tunisia \\ Aron Kondoro, Royal Institute of Technology, Stockholm, Sweden \& University of Dar Es Salam, Tanzania \\ Anastasia Anagnostou, Brunel University London, Uxbridge, UK \\ Amleset Kelati, University of Turku, Turku, Finland \& Royal Institute of Technology, Sweden \\ Shililiandumi Naiman, University of Dar es Salaam, Dar es Salaam, Tanzania \\ Simon J.E. Taylor, Brunel University London, Uxbridge, UK \\ Nerey Mvungi, University of Dar es Salaam, Dar es Salaam, Tanzania \\ Hannu Tenhunen, Royal Institute of Technology, Kista, Sweden
}

\begin{abstract}
This article describes a framework for load shedding techniques using dynamic pricing and multiagent system. The islanded microgrid uses solar panels and battery energy management system as a source of energy to serve remote communities who have no access to the grid with a randomized type of power in terms of individual load. The generated framework includes modeling of solar panels, battery storage and loads to optimize the energy usage and reduce the electricity bills. In this work, the loads are classified as critical and non-critical. The agents are designed in a decentralized manner, which includes solar agent, storage agent and load agent. The load shedding experiment of the framework is mapped with the manual operation done at Kisiju village, Pwani, Tanzania. Experiment results show that the use of pricing factor as a demand response makes the microgrid sustainable as it manages to control and monitor its supply and demand, hence, the load being capable of shedding its own appliances when the power supplied is not enough.
\end{abstract}

\section{KEYWORDS}

Demand-Response Scheme, Dynamic Pricing, Load Shedding, Multi Agent System, PV, Smart Microgrid

\section{INTRODUCTION}

The aging grid technologies coupled with the need for a greener energy system have urged the development of the smart grid. Information and Communication Technologies (ICT) are the heart of the smart grid. The smart grid is considered as a system of systems that engenders a plethora of advanced and smart applications such as distributed intelligence, smart metering infrastructure, demand response schemes, and self-healing (Bayindir, Colak, Fulli, \& Demirtas, 2016). According to (Zaballos, 
Vallejo, \& Selga, 2011), the smart grid is an electricity network that can intelligently and smartly integrate the actions and users connected to it (generators, consumers, transmitters, distributors and those that do both) so as to efficiently deliver sustainable, economic and secure electricity supplies.

Developing countries are facing arduous challenges to modernize the aging grid due to, among others, poor ICT infrastructure unregulated energy market. For instance, the Tanzania Electric Supply Company (TANESCO), which is the sole supplier company of the electricity in Tanzania, the transmission side, is the part, which has been implemented in the process of monitoring and controlling with smart grid and lesser extent to the primary distribution side of the grid system. There is still a need to automate the control of electric power to increase efficiency in all aspects of the electric power system, optimize cost to consumers and reduce the number of staff and human errors. In addition, the use of renewable energies such as solar and the wind is more valuable in the utilization and provision of electricity in places without access to the national grid. When the smart network system has been integrated with renewable energies as a source of power, this is referred to the as smart microgrid. According to Kihwele \& Kyaruzi, (2004), microgrid system is capable of rapidly detecting, controlling, managing, analyzing and responding to various perturbations in the network by integrating advanced control methods such as agent-based systems.

The control and management of distributed energy systems using multi-agent systems in the smart grid have been seen to work effectively in the provision of autonomous actions. The study by Jiang, (2006) discussed that agent-based system can be applied in the management of distributed energy systems including demand-side management, storage, and generation. Another use of multiagent systems has been implemented in the simulation of discrete event emergency medical services in London hospitals, (Anagnostou, Nouman, \& Taylor, 2013). Other sectors by which multi-agent systems can be applied are e-health, transportations, and infrastructure.

In microgrid systems, the role of control is important for reliable communication, efficiency operations, and autonomous actions. The level of control and monitoring in microgrid depends on different aspects incorporated such as latency, memory consumption, security issues and power management. Normally, the microgrid can be either operates in synchronous mode (connected to the grid) or asynchronous mode (islanded). Figure 1 described the Direct Current (DC) microgrid concept based on an islanded mode with solar as a renewable source of energy. Some advantages of microgrid systems are increasing reliability, money saving, revenue generation and aiding economic growth.

Figure 1. DC Microgrid control system

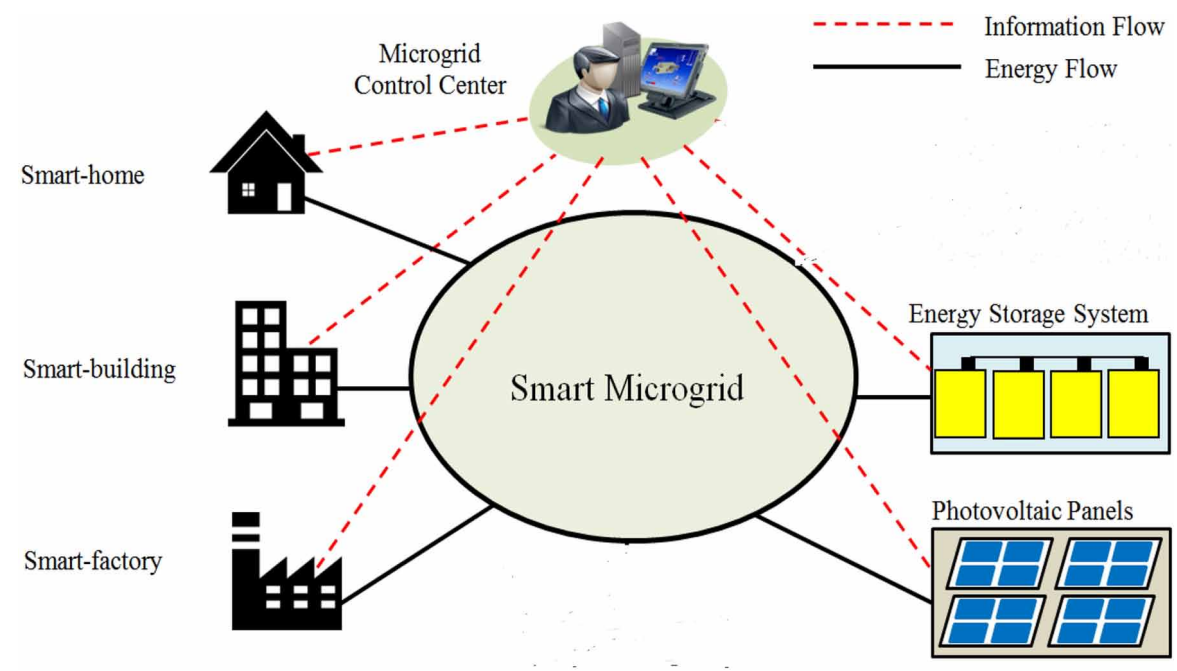


This work is an extension of our previous paper (Rwegasira et al., 2017). Specifically, a demand response scheme is proposed to reduce the energy bill for individual houses. A dynamic pricing algorithm is proposed to shed non-critical loads and to reduce the peak to average energy consumption. The dynamic pricing algorithm permits a user with surplus energy to earn money by selling unused energy when the prices climb up. The rest of the paper is organized as follows: Section 2 describes related work. Problem Statement is formulated in Section 3. The mathematical models for the various blocks in a DC microgrid are elaborated in Section 4. Section 5 details the multi-agent system for control and management of the DC microgrid. Simulation results using Repast are discussed in Section 6. Finally, Section 7 concludes the paper.

\section{RELATED WORK}

It is well accepted that peaks of energy consumption or the decrease of power generation may cause a power outage, grid instability, frequency variations, etc. Load-shedding and energy storage system are two well-known techniques to shave power peaks and increase grid stability (Seethalekshmi, Singh, \& Srivastava, 2011). Load shedding temporally eliminates some loads out of the system during peak demands. Load-shedding techniques are applied on the customer side with the objective of reducing the electricity bills. In the DC microgrid, prioritization strategies are used to prevent power outage for critical loads. In Xu, Liu, Chen, \& Gao, (2016), the authors proposed an optimal load shedding using Markov decision process for an islanded microgrid. A connected microgrid is at the risk of sever islanding in the event of a fault in the main-grid. Load shedding techniques for severely islanded microgrid are viable to prevent instability and to match supplies with demands (Das, Nitsas, Altin, Hansen, \& Sorensen, 2017; D'Agostino et al., 2017).

In the DC microgrid, the intermittency problem of solar energy is warded off using batteries energy storage system (BESS) (Fu et al., 2013). In industrial settings, peak demands and cost savings can be shaved using BESS coupled with optimal sizing (Oudalov, Cherkaoui, \& Beguin, 2007). Data centers are as energy-hungry facilities in the ICT industry in which batteries are considered as the suitable candidate to lower the electricity bill and reduce peak power demands. A cost-efficient centralized BESS with partial discharge that accounts for the nonlinearity of the battery capacity and its reliability is developed by (Aksanli, Pettis, \& Rosing, 2013).

Demand side management is a factor, which goes in parallel with the provision of constant and efficient power to the end users. The importance of demand response on consumer side has been addressed in Ciara, The, Engineering, Supervisor, \& Duignan, (2011) to describe how it can be in cooperated with the grid for maximum production of the electricity. It involves reducing electricity use through activities or programs that promote electric energy efficiency or conservation, or more efficient management of electric energy loads. (Saini, 2007) Described on how demand response can have a greater impact on the society with respect to energy usage and utilization.

Multi-agent system, MAS, has become popular in control and optimization (Leitão, 2009) (Lee \& Kim, 2008). In the energy sector, MAS has been applied to, for instance, control, optimize, simulate, and manage the smart grid (Merabet et al., 2014) and microgrid (Kantamneni, Brown, Parker, \& Weaver, 2015). The control of islanded and grid-connected microgrid with distributed energy resources, DERs, is a complex task. To create an autonomous microgrid, proposed a two-layer control algorithm combined with MAS. Three types of agents were used: a local agent, a regional agent and a service agent. The DER unit is controlled and monitored by the local agent. A regional agent controls all local agents within a given region. Finally, the service agent provides services, e.g. weather forecast, to both local and regional agents. In residential areas with renewable energy, decentralized coordination and load-shedding among houses are treated by (Celik, Roche, Bouquain, $\&$ Miraoui, 2017). The architecture is articulated around an aggregator to dynamically change the price. The authors considered controllable and non-controllable loads for operation scheduling. They further defined two agents: home agent and aggregator agent. Home agents use a genetic algorithm 
to control the operation of the controllable appliance with the aim to reduce the electricity bill. Logenthiran, Srinivasan, Khambadkone, \& Aung, (2012) Presented the multi-agent for real operation in a microgrid whereby the focus was on central scheduling and demand-side management. The model formulated based on the power generated and those consumed by the battery as well as the loads. In the modeling of DC microgrid, three main areas of concentration are generation part (source of power), storage part (battery) and the consumption part (loads). In modeling of the source of power, the main characteristics are the (current vs voltage) I-V and (power vs voltage) P-V behaviors. For storage modeling, the focus is on charging and discharging behaviors while on the consumer side, the most case scenario depends on the random generation of power and demand-side management. In this research, the modeling focus on solar and Photovoltaic (PV) panels' characteristics with respect to sun irradiations, battery storage with respect to State of Charge (SoC) while on load the focus is on uniform distribution with respect to time $t$.

\section{PROBLEM STATEMENT}

Access to reliable and affordable electricity is still a problem in Tanzania, especially in rural communities. According to Mwinyiwiwa, Kivaisi, \& Msoka, (2013), only 14\% of the Tanzanian population has access to electricity in rural areas. At the same time, the increase of productive investments has also increased the demand for electricity. More people need access to quality healthcare, communication, and education which all depend on a reliable supply of electricity. TANESCO, the main publicly-owned supplier of electricity in Tanzania, fails to satisfy this demand (Peng \& Poudineh, 2017). As a result of this, the Renewable Energy Agency (REA) and other solar power companies such as Helvetic Solar, TAREA, and Ensol have invested in solar technologies and projects in Tanzania. These efforts have helped many communities where they have been implemented (Couderc, 2017; Aly, Jensen, \& Pedersen, 2017; Jadhav, Chembe, Strauss, \& Van Niekerk, 2017).

However, despite these efforts, many of these solar projects suffer from control and optimization challenges. There is still an imbalance between the supply and demand for electricity. Sometimes the demand exceeds the capacity of the solar implementations. This can cause instabilities in the system and reduce the quality of power that is generated. In order to deal with this situation, skilled people are used to controlling and operating these solar implementations. They monitor and make sure that every part of the system is working. They also manually respond to any events that may overload the system. This process tends to be inefficient and slow. As a result, people cannot reliably depend on the availability of electricity at all times.

In order to solve these challenges, there is a need for more autonomous and reliable control mechanisms to balance supply and demand of electricity. Solar-based microgrid in these communities needs new approaches for automatic load scheduling as well as peer-to-peer power-sharing mechanisms in cases of excess power. Existing approaches depend on centralized architectures where one component controls the process (Hatziargyriou, Asano, Iravani, \& Marnay, 2007). These approaches do not scale well once the scope of the microgrid increases with demand factors. In addition, they introduce single points of failure that reduce the reliability and resilience of the whole system. There is a need for more decentralized mechanisms which can also offer other desirable features such as fault detection and tolerance, self-healing and dynamic pricing (Olivares et al., 2014).

\section{MATHEMATICAL MODELS FOR A DC-MICROGRID}

\subsection{Microgrid-Kisiju Pwani Model}

The need of modeling of any system is very important for the success and predictions of the results. The work by (Mwinyiwiwa et al., 2013), focus on the production of power through photovoltaic panels. This section explains how the modeling of solar, battery and loads have been done in order to 
achieve load shedding and demand response based on power and price. Table 1 shows the algorithm and the states which have been used to model the work.

\subsubsection{Solar Modelling With Power Consumption}

The means of converting the solar energy into a usable amount of direct current (DC) electricity can be done through the absorption of sunlight into the solar panels. Modelling of the solar panels is a common solution when describing different characteristics and behavior of solar. This characteristic of the solar panels are normally based on the voltage, illuminations and temperate of the surroundings (Chen, 2011).

To compute the altitude and azimuth angles, (1) and (2) were used:

$$
\alpha=a \sin ^{-1}\left\{\sin \left(L * \frac{\pi}{180}\right) \times \sin \left(\delta * \frac{\pi}{180}\right)+\cos \left(\delta * \frac{\pi}{180}\right) \cos \left(L * \frac{\pi}{180}\right) \cos \left(\omega * \frac{\pi}{180}\right)\right\}
$$

Table 1. Algorithm for the DC microgrid

\begin{tabular}{|c|c|c|c|c|}
\hline Algorithm & PV Solar panel & Storage Battery & Cri.Load & Non-Cri.Load \\
\hline Function & $\begin{array}{l}\text { Perform load } \\
\text { shedding based on } \\
\text { demand, Display } \\
\text { the price on hourly } \\
\text { basis }\end{array}$ & $\begin{array}{l}\text { State of charge }(\mathrm{SoC}) \\
\text { of the battery }\end{array}$ & $\begin{array}{l}\text { Maintain the } \\
\text { power level, no } \\
\text { shedding }\end{array}$ & $\begin{array}{l}\text { Control the power usage on the } \\
\text { allocated devices for shedding }\end{array}$ \\
\hline Action & $\begin{array}{l}\text { Provide power to } \\
\text { the microgrid }\end{array}$ & $\begin{array}{l}\text { Act as a backup of } \\
\text { main solar to provide } \\
\text { power to the loads }\end{array}$ & $\begin{array}{l}=\text { load profiling at } \\
\text { certain time. }\end{array}$ & $\begin{array}{l}=\text { load profiling at certain time. } \\
\text { Range of the power consumption of } \\
\text { the devices } \\
\text { Important devices: Lights, } \\
\text { fridge,TV } \\
\text { Non important devices: AC, } \\
\text { washing machine }\end{array}$ \\
\hline Rules1 & $\begin{array}{l}\mathrm{P}_{\mathrm{s}=} \text { power supply, } \\
\mathrm{P}_{\text {threshold }} \text { Threshold } \\
\text { power }\end{array}$ & \multicolumn{3}{|c|}{ Power supply and consumption } \\
\hline & $\mathrm{P}_{\mathrm{s}}>\mathrm{P}_{\text {threshold }}$ & SoC battery $>=50 \%$ & Switch ON & Switch ON \\
\hline & $\mathrm{P}_{\mathrm{s}}<\mathrm{P}_{\text {threshold }}$ & SoC battery $>=50 \%$ & Switch ON & Isolate from solar, get from storage \\
\hline & $\mathrm{P}_{\mathrm{s}}<\mathrm{P}_{\text {threshold }}$ & SoC battery $<=50 \%$ & Switch ON & $\begin{array}{l}\text { Isolate from storage, get from its } \\
\text { own battery. }\end{array}$ \\
\hline \multirow[t]{3}{*}{ Rules 2} & & \multicolumn{3}{|l|}{ Algorithm of the price } \\
\hline & $\begin{array}{l}\text { Price is high: } \\
\text { If the demand } \\
\text { is high than the } \\
\text { supply }\end{array}$ & & & $\begin{array}{l}\text { Control the devices and either } \\
\text { (i) switch off the Non important } \\
\text { devices } \\
\text { (ii) use your own battery } \\
\text { (iii) if you have surplus, sell to the } \\
\text { grid }\end{array}$ \\
\hline & $\begin{array}{l}\text { Price is low: } \\
\text { Demand is low } \\
\text { than the supply }\end{array}$ & & & $\begin{array}{l}\text { Switch all the devices } \\
\text { Reserve the battery power for future } \\
\text { use }\end{array}$ \\
\hline Results & $\begin{array}{l}\text { Power } \\
\text { consumption, price } \\
\text { against time }\end{array}$ & $\begin{array}{l}\text { Power consumption } \\
\text { against time }\end{array}$ & & $\begin{array}{l}\text { Power consumption, price against } \\
\text { time }\end{array}$ \\
\hline
\end{tabular}


$\theta=\sin ^{-1}\left\{\frac{\cos \left(\delta * \frac{\pi}{180}\right) \sin \left(\omega * \frac{\pi}{180}\right)}{\cos \left(\alpha \frac{* \pi}{180}\right)}\right\}$

where $a$ is the apparent solar time, $L$ the latitude in degree, $\delta$ the declination angle, and $\omega$ the hour angle.

\subsubsection{Solar Modeling With Power Production}

To compute the total solar irradiation of the sun, (3) was also used:

$S_{i r r}=(1+C) A e^{\left\{-k / \sin \alpha \frac{* \pi}{180}\right\}}$

where $\mathrm{A}, \mathrm{C}$, and $\mathrm{k}$ are factors, which depends on the number of solar cells, calculated as:

$$
\begin{aligned}
& A=1160+\left\{75 \sin ^{-1}\{(360 / 365) \times(N-275)\}\right\} \\
& k=0.174+\left\{0.035 \sin ^{-1}\{(360 / 365) \times(N-100)\}\right\} \\
& C=0.095+\left\{0.04 \sin ^{-1}\{(360 / 365) \times(N-275)\}\right\}
\end{aligned}
$$

The calculation of the PV model was based on several constant values as tabulated in Table 2, which lead to having (7):

\section{Table 2. Solar cell parameters}

\begin{tabular}{|l|l|}
\hline \multicolumn{1}{|c|}{ Parameter } & \multicolumn{1}{c|}{ Constant Value } \\
\hline Number of Suns, G & $1000 \mathrm{~W} / \mathrm{m}^{2}$ \\
\hline Temp, $T$ & 273 \\
\hline Boltzmann's const, K & $1.38 \mathrm{e}-23$ \\
\hline Charge on an electron,q & $1.60 \mathrm{e}-19$ \\
\hline Diode quality, A & 1.2 \\
\hline Band gap voltage, Vg & 1.12 \\
\hline Open cct voltage per cell a temperature $T 1(25)$, Voc_T1 & $32.9 \mathrm{~V}$ \\
\hline Short cct current per cell at temp $T 1$, Isc_T1 & 8.21 \\
\hline Open cct voltage per cell at temperature $T 2(75)$, Voc_T1 & 29.9 \\
\hline Short cct current per cell at temp $T 2(75)$, Isc_T2 & 6.62 \\
\hline array working temp, $T a K$ & $T a K=273+T a C$ \\
\hline reference temp, $T r K$ & $T r K=273+25$ \\
\hline
\end{tabular}


$\operatorname{Ian}=I s c_{T 1} * \operatorname{Suns}^{*}(1+a *(T a K-T 1))-I r *\left(\exp \left(\frac{(V c+I a R s)}{V t_{T a}}\right)-1\right)$

where by:

$$
\begin{aligned}
& \mathrm{Vt}_{\mathrm{Ta}}-\mathrm{A}^{*} \mathrm{kt} / \mathrm{q} \\
& I r=I r_{T 1} *\left(\frac{T a K}{T 1}\right) \cdot(3 / A) * e^{\left(-b^{*}\left(\frac{1}{T a k}-\frac{1}{T 1}\right)\right)} \\
& b=V g * q /\left(A^{*} k\right) \\
& I r_{T 1}=\frac{I s c_{T 1}}{\left(\exp \left(\frac{V o c_{T 1}}{A^{*} V t_{T 1}}\right)-1\right)}
\end{aligned}
$$

\subsubsection{Solar Modeling with Pricing Control}

The calculation of price-ahead was controlled by different parameters include: number of houses in the microgrid $(\mathrm{N})$, predictable available energy for the next hour $(\mathrm{E})$, predictable power at the next hour (a vector of length $\mathrm{N}$ ), the maximum and minimum price of in the microgrid, $\left(\mathrm{q}_{\max }, \mathrm{q}_{\text {min }}\right)$ a safe margin energy $(\zeta)$, the step of the price increase, $(\mathrm{L})$ and the current price $\left(\mathrm{q}_{\mathrm{i}}\right)$.

The algorithm works as follows: At the $\mathrm{i}^{\text {th }}$ time and at the kth day, the algorithm computes the consumed power by all $\mathrm{N}$ houses. This value is checked against the produced energy. In case the total energy demands are very close to the generated energy, then the price for the next interval of time is increased by a constant step $T$. In case the demands in energy is less than the produced energy, then the prices are lowered by a constant step $T$. The algorithms guarantees that the price will not leave the margin, that is $q_{i}(k) \in\left[\begin{array}{ll}q_{\min } & q_{\max }\end{array}\right]$. The algorithm should maintain high values for $q_{\max }$ so that only critical loads are powered on.

Function price-control $(i, N, k, \zeta)$

$$
\begin{gathered}
P_{i}^{d}(k) \leftarrow \sum_{j=1}^{N} p_{j}^{i}(k) ; / / \text { Compute the current energy consumption } \\
E_{i}^{p}(k) \leftarrow \sum_{j=1}^{N} e_{j}^{i}(k) / / \text { Compute the actual available power } \\
\{ \\
\text { if }\left(P_{i}^{d}(k)+\zeta \geq E_{i}^{p}(k)\right) \\
q_{i+1}(k) \leftarrow \min \left(q_{i}(k)+T, q_{\max }\right) / / \text { increase the price }
\end{gathered}
$$


else if $\left(P_{i}^{d}(k)+\zeta<E_{i}^{p}(k)\right)$

$q_{i+1}(k) \leftarrow \max \left(q_{i}(k)-T, q_{\text {min }}\right) / /$ reduce the price

else

$$
q_{i+1}(k) \leftarrow q_{i}(k)+T
$$

endif

\}

return $q_{i+1}$

\}

\subsubsection{Storage Modeling}

In a PV- microgrid, the electricity generated by PV panels depends on the weather condition, orientation of the panels, etc. This and other factors create electricity generation intermittency. To circumvent this problem, batteries should be used to store the surplus energy and used when the PV panels do not produce enough electricity for the house. Chemical batteries are the widely used technology in the renewable energy sector. Electrolyte, anode and cathode are the most important elements that determine the electrical behavior of the battery. During charging, chemical battery converts electricity into chemical energy using the principle of oxidation-reduction. Batteries are charged and discharged using a solar charge controller (SCC). Figure 2 shows the connection of a solar charge controller to the PV panel, a battery and DC appliances inside a residence.

The solar charge controller is an embedded system that implements a charging/ discharging algorithm along with other protection features such as protection against overcharge and undercharges (c. Batteries have several parameters that depend on the battery-type, applications, etc. In DC-microgrid and for lead-acid battery, the most important parameters are SoC (State of charge), DoD (depth of discharge), rated capacity, voltage rating, capacity, Coulombic efficiency, and cycle lifetime. The DoD

Figure 2. Connection of a solar charge controller

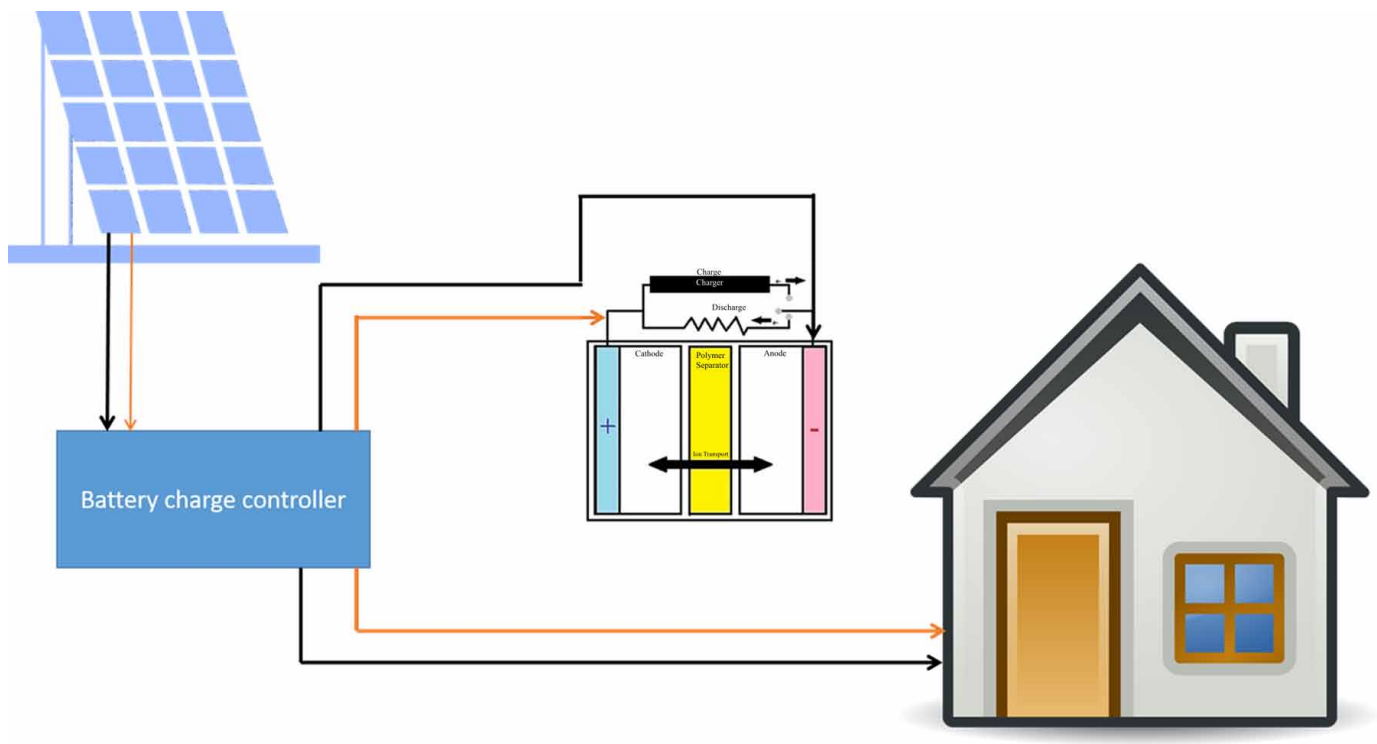


for a lead acid battery should not drop below $50 \%$ of its rated capacity. The capacity of the lead-acid battery can be determined using Peukert's law as given in equation (12):

$$
C_{b a t}=I_{d} t
$$

where $C_{b a t}$ is the battery capacity in Amp-hour, $I_{d}$ is the discharge current (which is supposed to be constant), and $\alpha$ is the Peukert's coefficient. The original Peukert's law has been found inaccurate by (Doerffel \& Sharkh, 2006) and they proposed several empirical equations for lead-acid battery.

In this work, SoC is the most appropriate parameter that needs to be continuously tracked for home energy management system. For a lead-acid battery, SoC can be determined using the dynamic model developed by (Ceraolo, 2000) which is shown in Figure 3: Lead-acid equivalent circuit model. The charging and discharging of the battery has been calculated using equation (13):

$$
C(t)=C(t-1)+\left\{\frac{\Delta t \times \Psi_{b}(t)}{V_{b}(t)} \times P_{\text {rew }}(t)-P_{u}(t)\right\}
$$

where $P_{u}(t)$ is the renewable battery power, $P_{\text {rew }}(t)$ is the total renewable power, $V_{b}(t)$ is the voltage of the battery terminals at time t, $\Psi_{b}(t)$ is the battery efficiency, and $C(t)$ and $C(t-1)$ are the battery charges at time $\mathrm{t}$ and $\mathrm{t}-1$ respectively.

\subsubsection{Load Modeling}

With modeling of the load, the main attribute is to generate the random values at given number of intervals. Equation (13) was used which based on the uniform distribution with a specified number of values needed:

$$
r=A i+(A i+B i) * \operatorname{rand}(N, 1)
$$

\section{Figure 3. Lead-acid equivalent circuit model}

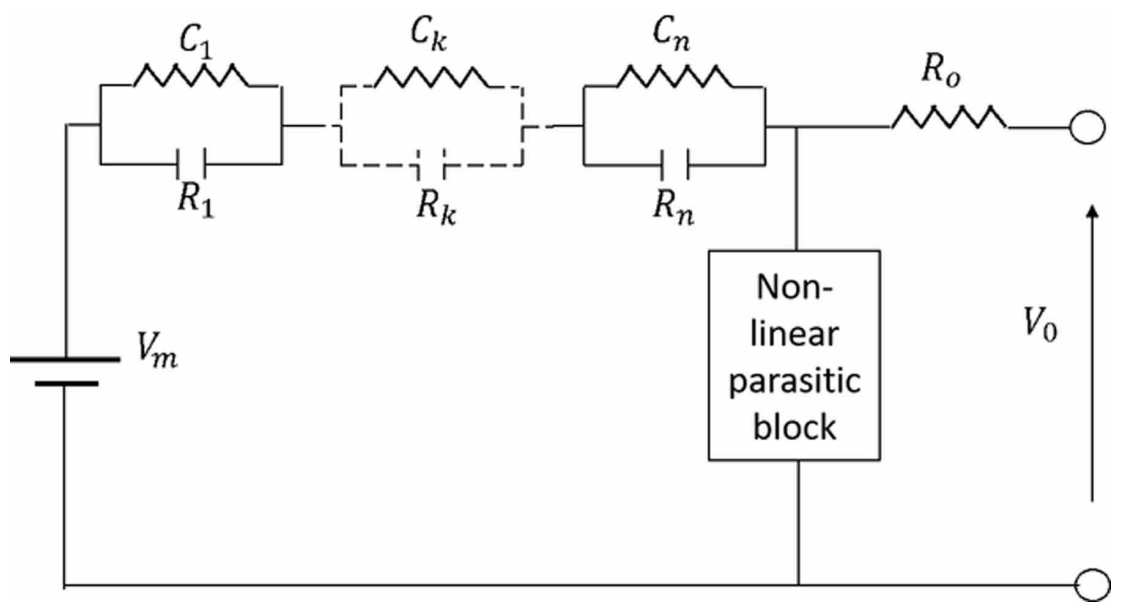


where A, B represent intervals of the random numbers to be generated, $\mathrm{N}$ random generated numbers, and $i$ the ith number generated.

Moreover, the two scenario functions for buying and selling power to grid are described as follows.

\subsubsection{First Scenario: Buying From the Grid}

The load (house) is responsible for energy control and monitoring. The keeps on monitoring the status of the battery (SOC) to predict, in an hour-ahead, the available power. In case the energy stored in the local batteries does not cover the predicted need, then the agent checks for the energy prices in the next hour. If the prices are affordable, then the agent will buy the extra power from the micro-grid. In case the prices are high, the agent will power-off non-critical loads.

\subsubsection{Second Scenario: Selling to the Grid}

In case the energy stored in the available energy in one hour-ahead is significantly higher than the predicted demands, then the agent will check the current prices at the micro-grid. If the prices are high, then the agent can sell the surplus. The house can also decide to attach more battery and save the extra-power in case the prices are low.

The aspect of load categorization is based on important and less important appliances where by the user can decide to switch the device to reduce the cost when the price is high. Table 3 shows the types of the appliances selected for this work where by the light bulbs, TV and Fridge are important while the air conditioner is less important.

\section{IMPLEMENTATION OF MULTI-AGENT SYSTEM}

\subsection{Repast Simphony Platform}

In our simulation work, we used Repast simphony to develop and simulate multi-agent systems. Repast Symphony is a Java-based toolkit that offers different simulation platforms such as Java, Logo, Groovy and Statecharts, for developing agent-based models (Bragen, Collier, Murphy, Ozik, \& Tatara, 2012). It is an open source tool that allows to easily design and simulate dynamic systems that involve multiple interacting agents and provide the step by step simulation. Repast has already been used to model and simulate different applications and use cases in the electric power domain. It has been used to model and simulate the interaction of smart homes with distributed power generation in order to minimize individual power costs and peak power consumption (Kahrobaee, Rajabzadeh, Soh, \& Asgarpoor, 2012). It has also been used to simulate very complex and dynamic distributed electricity markets in smart grid scenarios where customers with competing goals and constraints buy and sell electricity to each other with dynamic prices (Kahrobaee, Rajabzadeh, Soh, \& Asgarpoor, 2014). Moreover, Repast in agent execution provides a tick driven synchronous and scheduler single thread approach while in terms of interaction it allows method calls and resource sharing.

Table 3. Appliances with their power consumption

\begin{tabular}{|l|l|l|}
\hline \multicolumn{1}{|c|}{ Device } & \multicolumn{1}{c|}{ Capacity } & Amount \\
\hline Light bulbs & $13 \mathrm{~W}$ & 6 \\
\hline TV & $40 \mathrm{~W}$ & 1 \\
\hline Fridge & $150 \mathrm{~W}$ & 1 \\
\hline Air Conditioner & $1000 \mathrm{~W}$ & 1 \\
\hline
\end{tabular}




\subsection{Agent Collaborations}

There are three agents in this microgrid, which are solar, storage and load. The load agents have their own solar and storage, which has similar characteristics like the main solar except that it, can perform load shedding. Figure 4 shows the set-up of the agents and their interconnection between each other. Table 2 also summarizes the functions of each agent implemented in the Repast.

\subsubsection{Solar Agent}

This is the main power supply to the battery and loads. The behavior of this agent is to obtain the solar radiation from the sunshine and generate the power from it. The higher the sunshine results in the maximum power production. The expected maximum power will be generated at noon where the sunshine is the highest peak. The solar agent learns the behavior of the environments through sun radiations and illuminations then produce an output of power. That action is autonomous and it changes according to the sunshine of the day. This agent is also responsible for charging the main battery up to the maximum level ( $80 \%$ of the $\mathrm{SoC})$ and then supplies the loads. Moreover, the distribution of power depends on the number of loads and their consumption of power per daily basis. The main solar is accountable for categorizing the critical and non-critical loads and to perform load shedding when the power is not sufficient. In addition, the demand response of the solar agent is focusing on how the loads are able to provide extra power to the main storage for continuous distribution of power. This is also responsible for the pricing control as described in the previous section.

The "ChargeController" function is the one with attributes to perform the control logic. It is responsible to control and monitor the status of the power consumptions supplied to the grid and notify the pricing function on whether to increase the price or decrease it. At every iteration, the systems keep on updating and checking the production. If the solar panels have enough power to distribute into the system, then the price will remain unchanged. Moreover, the control of the battery level for charging and discharging is done with this agent and in case there is an inefficient power supply, the following can be done: (1) increase the price and announce to the system, (2) disconnect the non-critical loads.

\section{Figure 4. Agent collaborations in DC Microgrid}

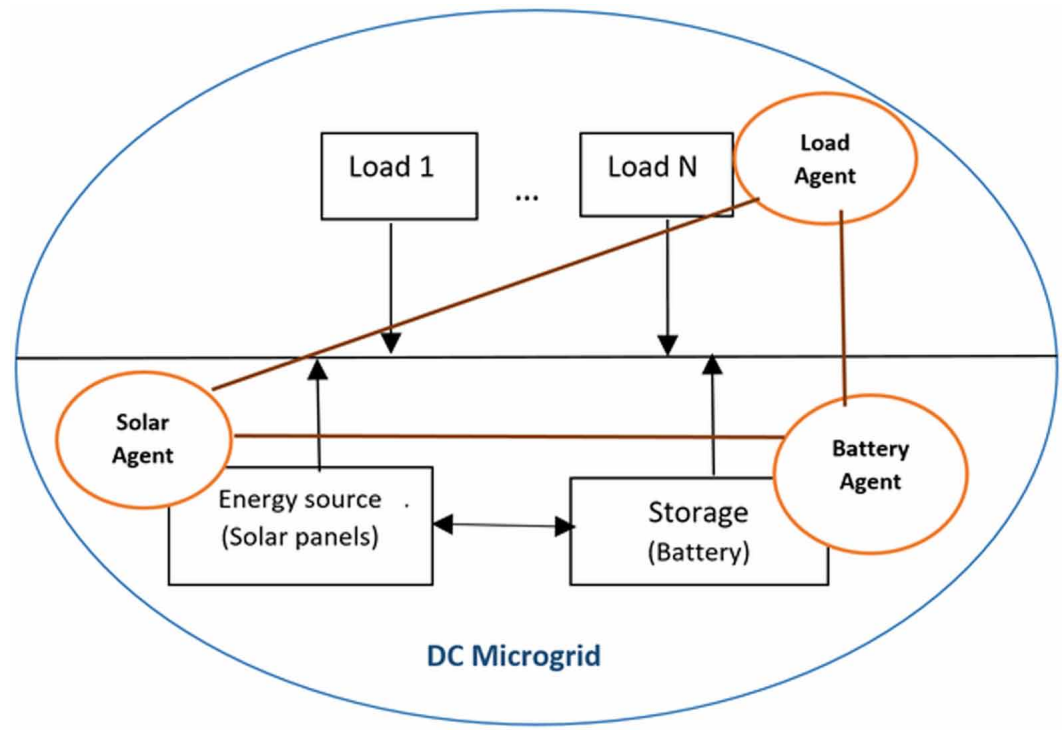




\subsubsection{Storage Agent}

The main task of this agent is the storage concept and act as a backup of the solar agent. It monitors the charging and discharging activities and ensures the constant provision of power to the critical loads. This agent provides power when the solar do not have sufficient power to support the loads. Extra power is also shared to this agent to make demand response scheme based on pricing effective and efficient. Moreover, each individual load agent has its own battery storage which has the following functions: (1) control the charging process, (2) determine the health of the battery, (3) forecast the power demand of the load, (4) prioritize the appliances, i.e. important and less important devices based on the available power either from local battery or the grid and (5) guarantee safe operation and optimal performance of the battery system.

The "SupplierBattery" function which extends to the "SolarBattery" function maintains the SoC of the Lead-acid characteristics and act as a backup into the main system. The main storage battery focus on controlling the overall system while the individual battery monitors the consumption of the individual house. The capacity of the individual load (house) is specified by the owner based on the consumption and need. The individual storage agent keeps on monitoring the consumptions and the level of the supplied power. If the load (house) has been disconnected, then the battery has to automatically switch on.

\subsubsection{Load Agent}

This agent has its own solar and storage for power usage where it can use it as per demand. The power consumption of each load is generated randomly per hours using (14). The load agent provides automatically extra power to the main source and responds to its own power when load shedding takes place. In addition, the load agent has a capability of either deciding to use its own power generated or the power from the grid.

The "RandomGeneratePower" function provides the owner of the grid to specify the maximum and minimum power each user. This was done in order to generate the load profiling based on the context of an electric company in Tanzania, but also to have the flexibility of the system. Apart from this, another function is the "consumer" function which focuses on demand and supply attributes. For every iteration, the agent has to monitor on the pricing behavior in the solar agent and decide on: (1) Switch off the battery and use the grid if the price is low, (2) Continue to use the power from its battery.

Also, depending on the availability of the charging capacity, the agent has to make shedding on the less important appliances. This is done through the "LoadPower" function which for every iteration it is able to anticipate the power consumption of the load to be used. Therefore, this will provide the time for important appliances to continue to be used. Table 4 summarizes the functions of each agent.

\section{Table 4. Functions of each agent}

\begin{tabular}{|l|l|l|l|}
\hline \multirow{4}{*}{} & \multicolumn{1}{|c|}{ Solar } & \multicolumn{1}{c|}{ Battery } & \multicolumn{1}{c|}{ Load } \\
\cline { 2 - 4 } & $\begin{array}{l}\text { Solar irradiation and } \\
\text { illumination of the sun }\end{array}$ & $\begin{array}{l}\text { Charging and } \\
\text { discharge }\end{array}$ & $\begin{array}{l}\text { Random values generated in } \\
\text { Kwh }\end{array}$ \\
\cline { 2 - 4 } & $\begin{array}{l}\text { Current production for 24V to } \\
48 \mathrm{~V} \text { dc. }\end{array}$ & $\begin{array}{l}\text { Status of the health of } \\
\text { charge }\end{array}$ & $\begin{array}{l}\text { Get excess power method, Run: } \\
\text { for running simulation and } \\
\text { Distribute power method }\end{array}$ \\
\cline { 2 - 4 } & Run: for running simulation & $\begin{array}{l}\text { Reserve the power for } \\
\text { future use }\end{array}$ & Distribute power method \\
\cline { 2 - 4 } & Distribute power method & & $\begin{array}{l}\text { Perform load shedding to its } \\
\text { appliances based on the demand }\end{array}$ \\
\cline { 2 - 4 } & $\begin{array}{l}\text { Charger Control, Supplier } \\
\text { function, power grid control }\end{array}$ & $\begin{array}{l}\text { Selling/buying the power to the } \\
\text { grid with respect to the price }\end{array}$ \\
\hline
\end{tabular}




\section{RESULTS AND DISCUSSION}

The results are demonstrated with 3 houses which have critical and non-critical loads. The simulation has been run with 100 tick counts, which is equivalent to 100 hours. The working voltage is $24 \mathrm{~V}$ and $48 \mathrm{~V}$ dc for individual and main storage battery respectively. When running the Repast, there are several parameters a developer has to insert based on the model. In our case Figure 5 shows some part of the parameters which for every running option, the user can change with respect to his/her targets, i.e. increased number of houses, storage level, price values, power from the source and be able to see how the load shedding will take place. In this case, when running different scenarios, it will then be possible to analyze the power consumptions in the microgrid and make plans as required especially on how long the grid will provide power to the loads. Sidewise, Figure 6 shows the 2-dimensional figure of the microgrid with a solar panel as a source, battery as storage and loads indicating critical and non-critical loads. For every step of the simulation, the changes of the power consumption and usage will also be changed in all agents until the indicated 100 ticks diminished. This is also one of the advantages of using the Repast simulation tool where the visualization of the output can be seen at each step of the simulation.

The price profile of the grid is an important feature for the forecasting demand in the country. The individual customer needs to know the plan of its usage upon knowing the ahead price in the grid. In Figure 7 and Figure 8 show the time-based price of the power and the next price ahead when there is shedding and without shedding. If at the peak hours and the power generation is not enough, the source agent can decide to disconnect the non-critical load and leave the critical load on the operation mode. In this case, it is easy for the customer to decide on its power consumption by automatically switching off its heavy-duty appliances or decided to connect with its own battery if it has enough storage capacity. From the Figure 7 it shows the price is high almost all times due to the shortage of power from the supplier. The parameter of the price increment will be set by the control center in

Figure 5. Part of the parameters

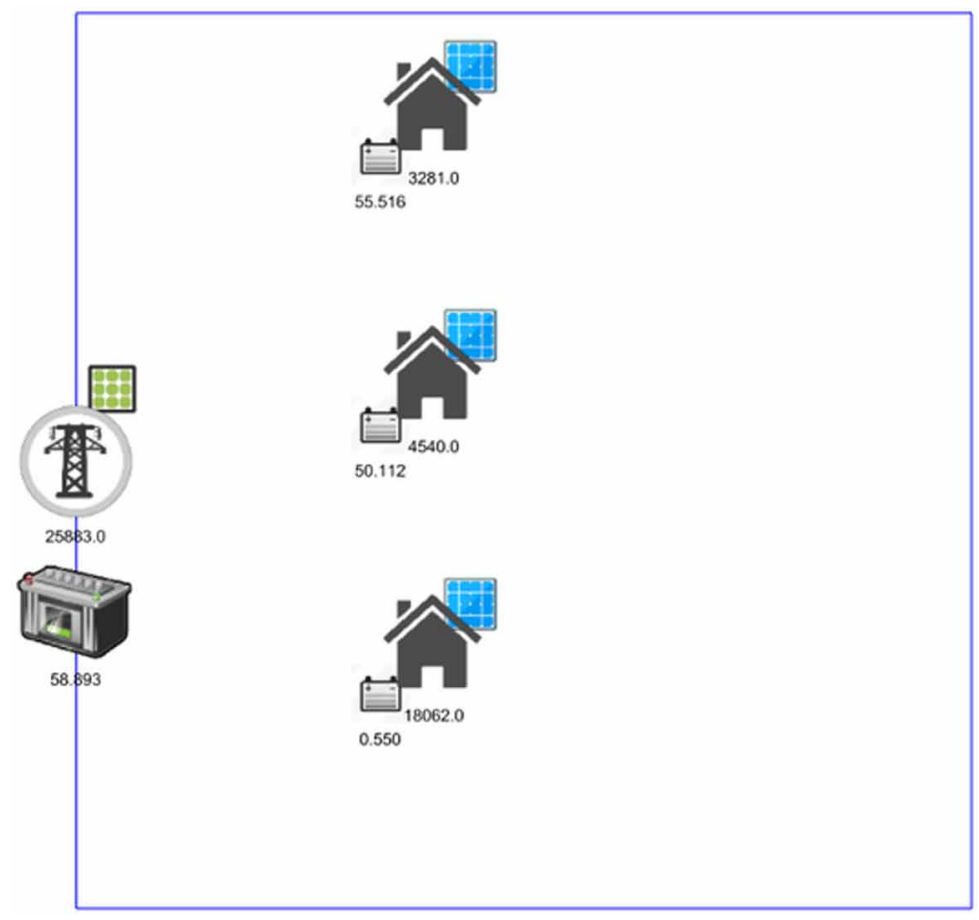


Figure 6. 2D visualization of the microgrid

\begin{tabular}{l} 
Consumer: Critical Load valuer: \\
300 \\
Default Random Seed: \\
850500914 \\
Main consumer: Max consumption: \\
25,000 \\
Main consumer: Min consumption: \\
15,000 \\
Normal consumer: Max consumption: \\
6,000 \\
Normal consumer: Min consumption: \\
2,000 \\
Number of consumers: \\
3 \\
Start date(DD/MM/YrYY): \\
$1 / 1 / 2017$ \\
Start time(HH:MM): \\
$06: 00$ \\
Supplier solar battery capacity(Amph): \\
40,000 \\
Supplier solar battery threshold: \\
50 \\
Supplier solar battery voltage(V): \\
\hline 38 \\
Supplier: Price increment (T): \\
\hline 10,000 \\
Supplier: Minimum price(Per Unit): \\
\hline 500 \\
\hline
\end{tabular}

which the price depends on several factors such as the consumption rates, the weather conditions as well as different offers in the grid system. Also in Figure 8 the price has been low most of the time with some few spikes going to high when the power was running down and this has happened due to the increase of supplier solar panels and battery storage capacity.

With respect to the community, the utilization of the demand response schema and price management provides the stability of the system and makes a better profit. The reason for this is due to the fact that majority of the users will keep on tracking the pricing profile and make use of electricity efficiently. Moreover, many users may decide to use their battery storages during peak hours and leave the grid only for critical loads such as hospitals and schools. In the long run, if every community can manage to control and monitor its own microgrid based on price control, then the effect of deficiency power will be decreased.

The load profile graphs can be seen in Figure 9 showing the shedding and non-shedding of the appliances to an individual house. In this manner, in the time of the highest price peak, the house 


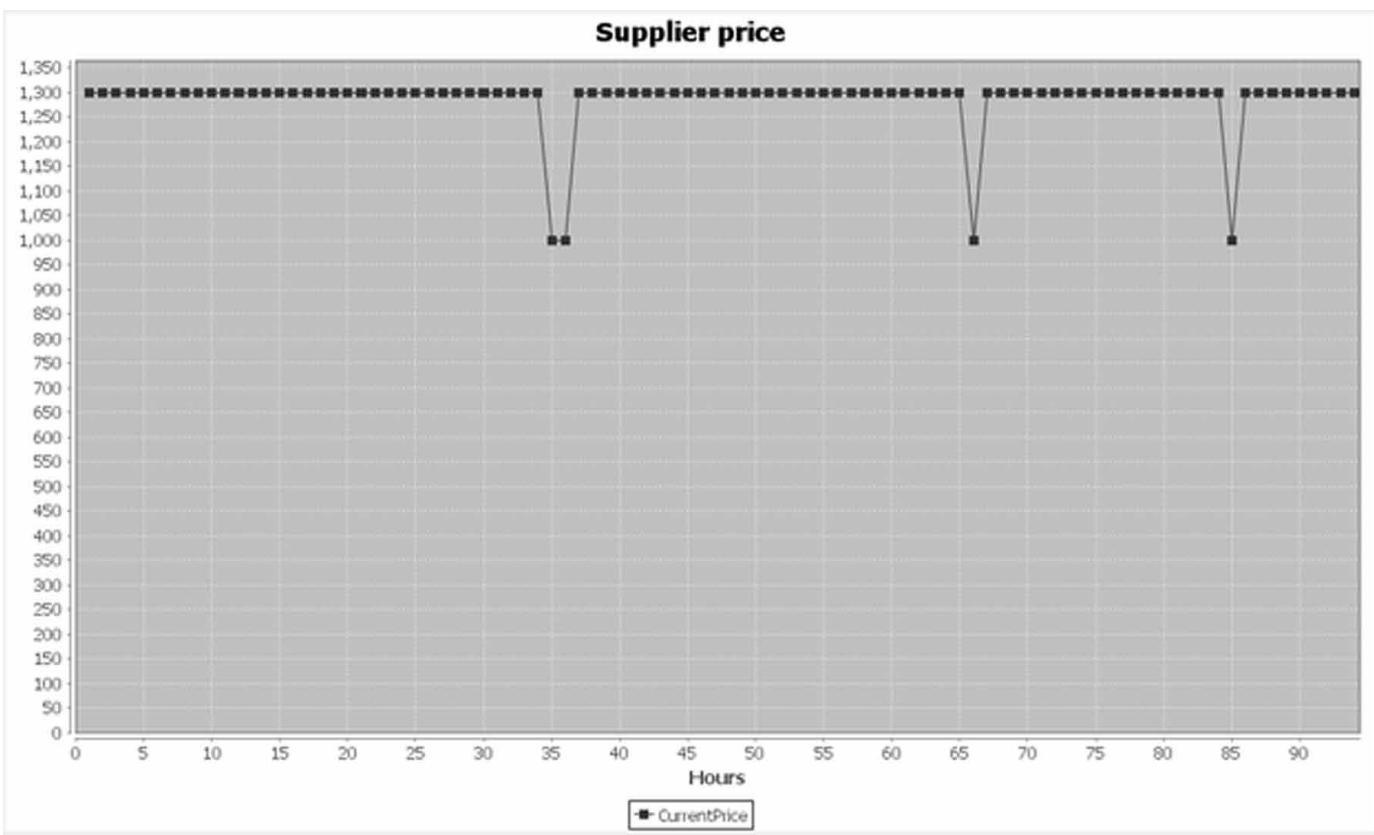

Figure 8. Price vs time without shedding

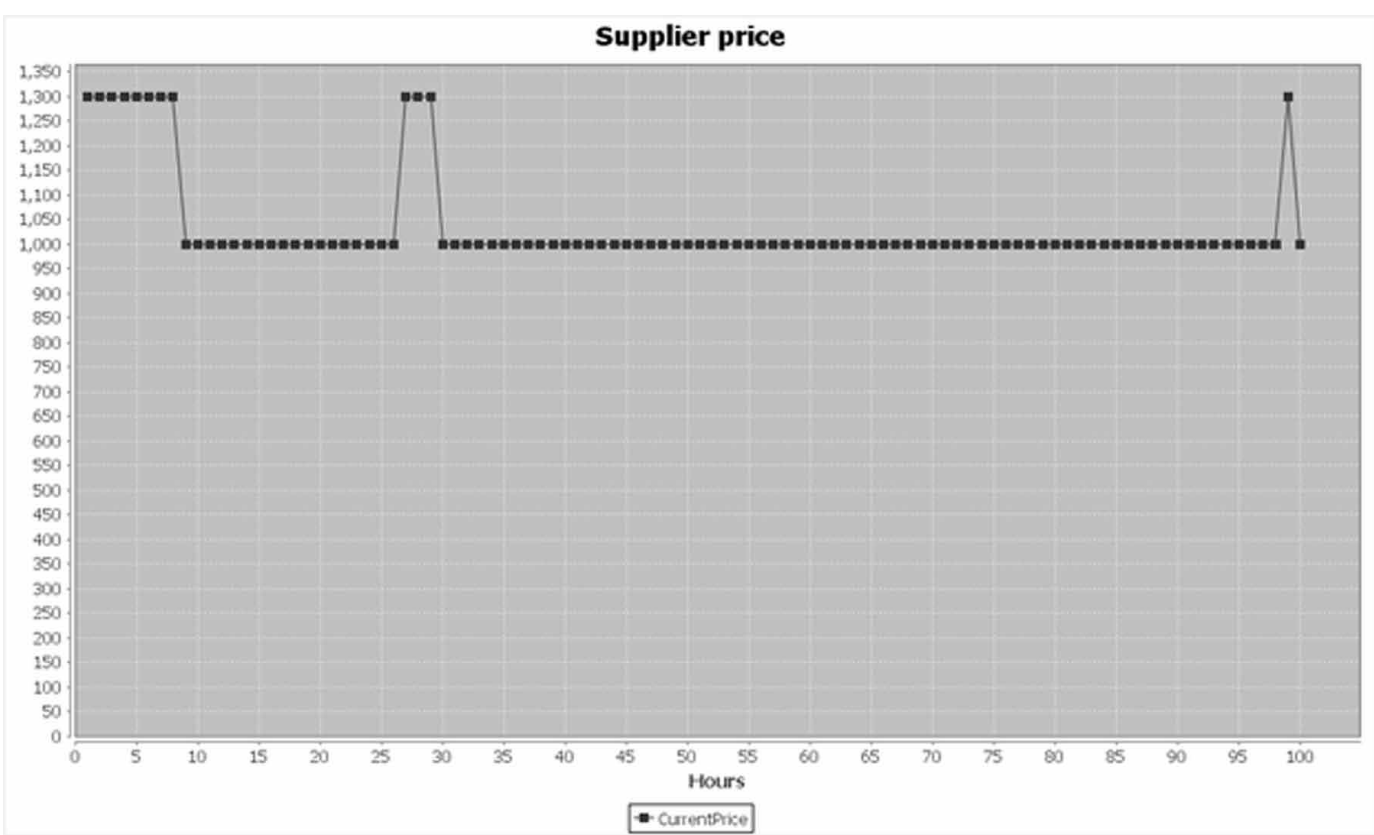

decides to switch off some of the less important appliances in order to reduce the cost. Therefore, the only option is either off operation or decide to use its own battery. With respect to the price to become low, it can be seen that the supplier has enough electricity to the supplier to consumer load and hence, no load shedding process. 


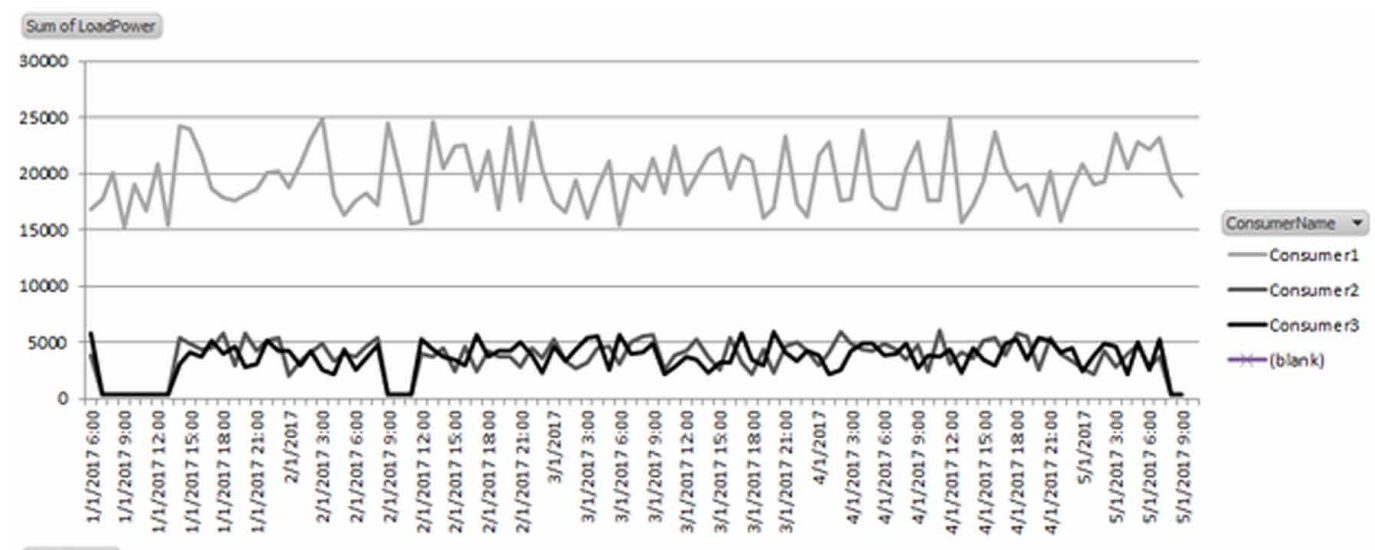

From Figure 10 when the load shedding takes place, the supplier continues to provide electricity to the critical load and cut off the non-critical loads. At the same time, the price of electricity was high due to that fact that it has less power to supply. This may be due to weather conditions, high demand and so on. Therefore, in this case, the non-critical loads decide to utilize its own battery and reduce the consumption through switch off air conditioner and just remained with the important appliances, i.e. TV, light and fridge. The spikes seen on the graphs are when the price was lowered by the supplier and hence, the non-critical loads return into the microgrid.

\section{CONCLUSION}

The design and implementation of microgrid systems depend much on the perfect modeling of its components. This work shows the effect of both load shedding and no load shedding on modeling of the solar driven DC microgrid with the effect of demand response based on pricing. The ideas of an individual load to disconnect the non-critical appliances have been seen to work successfully when

Figure 10. Consumer power consumption vs time with load shedding

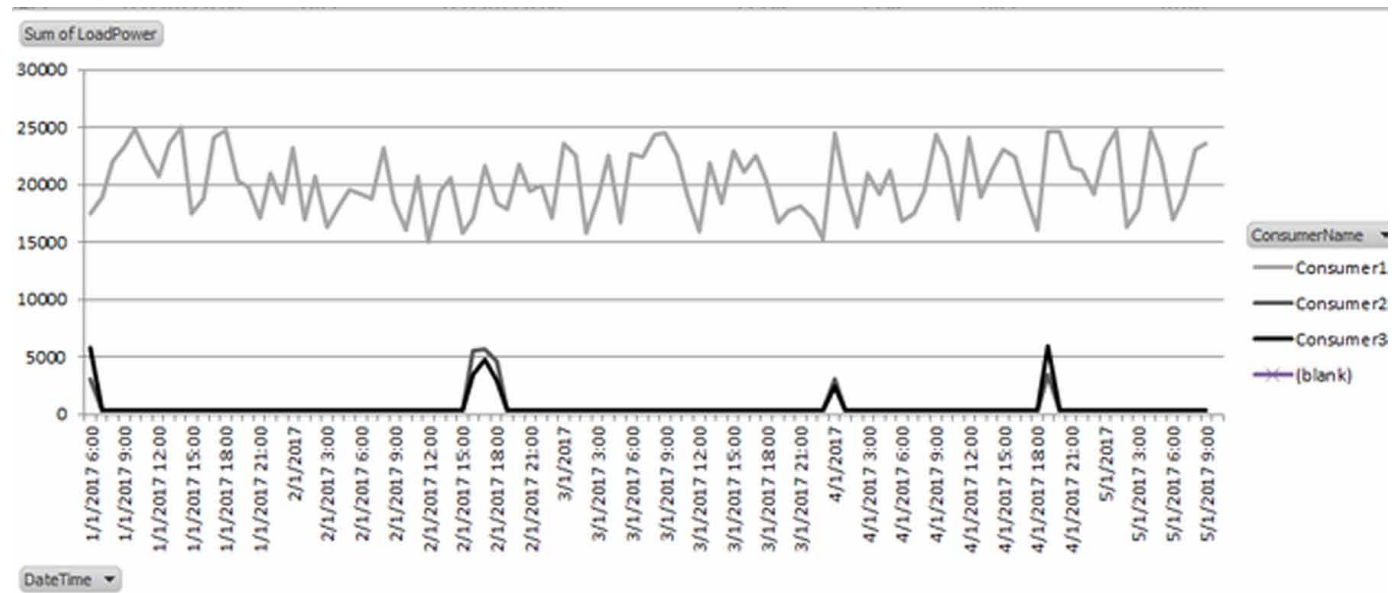


the DC-microsystem suffers from power scarcity. In addition, the use of battery management system for checking the DoD is important for the microgrid system to improve the battery health. With different numbers of houses and different parameters, using the multi-agent system, the solar agent can provide power to the microgrid and leave the critical load in a safe mode as well as make use of demand response to solve the issue of supplying and demanding. In addition, the effect of demand response can be achieved with load agents to provide extra power to critical appliances automatically.

\section{ACKNOWLEDGMENT}

This work is supported by the Swedish government through the SIDA project. 


\section{REFERENCES}

Aksanli, B., Pettis, E., \& Rosing, T. (2013). Architecting efficient peak power shaving using batteries in data centers. In Proceedings - IEEE Computer Society's Annual International Symposium on Modeling, Analysis, and Simulation of Computer and Telecommunications Systems, MASCOTS (pp. 242-253). doi:10.1109/ MASCOTS.2013.32

Aly, A., Jensen, S. S., \& Pedersen, A. B. (2017). Solar power potential of Tanzania: Identifying CSP and PV hot spots through a GIS multicriteria decision making analysis. Renewable Energy, 113, 159-175. doi:10.1016/j. renene.2017.05.077

Anagnostou, A., Nouman, A., \& Taylor, S. J. E. (2013). Distributed hybrid agent-based discrete event emergency medical services simulation. In Proceedings of the 2013 Winter Simulation Conference - Simulation: Making Decisions in a Complex World, WSC 2013 (pp. 1625-1636). doi:10.1109/WSC.2013.6721545

Bayindir, R., Colak, I., Fulli, G., \& Demirtas, K. (2016). Smart grid technologies and applications. Renewable \& Sustainable Energy Reviews, 66, 499-516. doi:10.1016/j.rser.2016.08.002

BragenM.CollierN.MurphyJ. T.OzikJ.TataraE. (2012). Repast. Error! Hyperlink reference not valid.Retrieved from http://repast.sourceforge.net/

Celik, B., Roche, R., Bouquain, D., \& Miraoui, A. (2017). Decentralized neighborhood energy management with coordinated smart home energy sharing. IEEE Transactions on Smart Grid, 3053, 1-6. doi:10.1109/ TSG.2017.2710358

Ceraolo, M. (2000). New dynamical models of lead-acid batteries. IEEE Transactions on Power Systems, 15(4), 1184-1190. doi:10.1109/59.898088

Ciara, B., The, D., Engineering, M., Supervisor, P., \& Duignan, R. (2011). Modelling Demand Response in the Residential Sector. University College Dublin.

Couderc, E. (2017). Solar energy: Hotspots in Tanzania. Nature Energy (Vol. 2). Macmillan Publishers Limited. doi:10.1038/nenergy.2017.121

D’Agostino, F., Massucco, S., Silvestro, F., Fidigatti, A., Monachesi, F., \& Ragaini, E. (2017). Low voltage microgrid islanding through adaptive load shedding. In Conference Proceedings - 2017 17th IEEE International Conference on Environment and Electrical Engineering and 2017 1st IEEE Industrial and Commercial Power Systems Europe. doi:10.1109/EEEIC.2017.7977861

Das, K., Nitsas, A., Altin, M., Hansen, A. D., \& Sorensen, P. E. (2017). Improved Load-Shedding Scheme Considering Distributed Generation. IEEE Transactions on Power Delivery, 32(1), 515-524. doi:10.1109/ TPWRD.2016.2536721

Doerffel, D., \& Sharkh, S. A. (2006). A critical review of using the Peukert equation for determining the remaining capacity of lead-acid and lithium-ion batteries. Journal of Power Sources, 155(2), 395-400. doi:10.1016/j. jpowsour.2005.04.030

Fu, Q., Hamidi, A., Nasiri, A., Bhavaraju, V., Krstic, S. B., \& Theisen, P. (2013). The Role of Energy Storage in a Microgrid Concept: Examining the opportunities and promise of microgrids. IEEE Electrification Magazine, 1(2), 21-29. doi:10.1109/MELE.2013.2294736

Hatziargyriou, N., Asano, H., Iravani, R., \& Marnay, C. (2007). Microgrids. IEEE Power \& Energy Magazine, 5(4), 78-94. doi:10.1109/MPAE.2007.376583

Jadhav, A. S., Chembe, D. K., Strauss, J. M., \& Van Niekerk, J. L. (2017). Status of Solar Technology Implementation in the Southern African Developing Community (SADC) Region. Renewable and Sustainable Energy Reviews, 73(February), 622-631. doi:10.1016/j.rser.2017.01.113

Jiang, Z. (2006). Agent-Based Control Framework for Distributed Energy Resources Microgrids. In 2006 IEEE/ WIC/ACM International Conference on Intelligent Agent Technology (pp. 646-652). doi:10.1109/IAT.2006.27

Kahrobaee, S., Rajabzadeh, R. A., Soh, L.-K., \& Asgarpoor, S. (2012). A Multiagent Modeling and Investigation of Smart Trading Features. IEEE Transactions on Smart Grid, 4(2), 1-10. 
Kahrobaee, S., Rajabzadeh, R. A., Soh, L. K., \& Asgarpoor, S. (2014). Multiagent study of smart grid customers with neighborhood electricity trading. Electric Power Systems Research, 111, 123-132. doi:10.1016/j. epsr.2014.02.013

Kantamneni, A., Brown, L. E., Parker, G., \& Weaver, W. W. (2015). Survey of multi-agent systems for microgrid control. Engineering Applications of Artificial Intelligence, 45, 192-203. doi:10.1016/j.engappai.2015.07.005

Kihwele, S., \& Kyaruzi, A. L. (2004). Effect of Poor Designing of Distribution System Case Study Tanzania Electric Supply Company Network. In 2004 International Conference on Power System TEchnologyPOWERCON, Singapore (pp. 1298-1302). doi:10.1109/ICPST.2004.1460202

Lee, J. H., \& Kim, C. O. (2008). Multi-agent systems applications in manufacturing systems and supply chain management: A review paper. International Journal of Production Research, 46(1), 233-265. doi:10.1080/00207540701441921

Leitão, P. (2009). Agent-based distributed manufacturing control: A state-of-the-art survey. Engineering Applications of Artificial Intelligence, 22(7), 979-991. doi:10.1016/j.engappai.2008.09.005

Logenthiran, T., Srinivasan, D., Khambadkone, A. M., \& Aung, H. N. (2012). Multiagent system for real-time operation of a microgrid in real-time digital simulator. IEEE Transactions on Smart Grid, 3(2), 925-933. doi:10.1109/TSG.2012.2189028

Merabet, G. H., Essaaidi, M., Talei, H., Abid, M. R., Khalil, N., Madkour, M., \& Benhaddou, D. (2014). Applications of Multi-Agent Systems in Smart Grids : A survey. In International Conference on Multimedia Computing and Systems (ICMCS) (pp. 1088-1094). doi:10.1109/ICMCS.2014.6911384

Mwinyiwiwa, B. M. M., Kivaisi, R. T., \& Msoka, C. (2013). Photovoltaic based Mini-Grid for Electrification of Remote Areas of Tanzania: The case of Kisiju-Pwani Village, Dar es Salaam, Tanzania.

Olivares, D. E., Mehrizi-Sani, A., Etemadi, A. H., Cañizares, C. A., Iravani, R., Kazerani, M., \& Hatziargyriou, N. D. et al. (2014). Trends in microgrid control. IEEE Transactions on Smart Grid, 5(4), 1905-1919. doi:10.1109/ TSG.2013.2295514

Oudalov, A., Cherkaoui, R., \& Beguin, A. (2007). Sizing and optimal operation of battery energy storage system for peak shaving application. In 2007 IEEE Lausanne POWERTECH, Proceedings, (1), 621-625. doi:10.1109/ PCT.2007.4538388

Peng, D., \& Poudineh, R. (2017). An appraisal of investment vehicles in the Tanzania's electricity sector. Utilities Policy, 48, 51-68. doi:10.1016/j.jup.2017.09.002

Rwegasira, D., Ben Dhaou, I., Anagnostou, A., Kondoro, A., Shililiandumi, N., \& Kelati, A. ... Tenhunue, H. (2017). A framework for laod shedding and demand response in DC microgrid using multiagent system. In 2017 21 st conference of Open Innovations Association (FRUCT) (pp. 284-289).

Saini, S. (2007). Demand-side management module. In Sustainable Energy Regulation and Policymaking for Africa (pp. 1-100). Retrieved from www.unido.org/fileadmin/media/documents/pdf/Module15.pdf?\%5Cn\%5Cn\%5Cn

Seethalekshmi, K., Singh, S. N., \& Srivastava, S. C. (2011). A synchrophasor assisted frequency and voltage stability based load shedding scheme for self-healing of power system. IEEE Transactions on Smart Grid, 2(2), 221-230. doi:10.1109/TSG.2011.2113361

Xu, Y., Liu, C.-C., Chen, Y., \& Gao, H. (2016). Dynamic load shedding for an islanded microgrid with limited generation resources. IET Generation, Transmission \& Distribution, 10(12), 2953-2961. doi:10.1049/ietgtd.2015.1452

Zaballos, A., Vallejo, A., \& Selga, J. M. (2011). Heterogeneous communication architecture for the smart grid. IEEE Network, 25(5), 30-37. doi:10.1109/MNET.2011.6033033 
Diana Rwegasira is a PhD student who is studying towards becoming an expert on modelling and simulation of smart grid. She will be graduating in December 2019. Diana has spent 3 years teaching first year students in programming courses at the University of Dar es salaam. Before that, she was taking her MSc in Computer science at University of Eastern Finland and Bsc. in Computer Engineering and IT at University of Dar es Salaaam. She is also interested in working at Educational Technologies (EdTech).

Imed Saad Ben Dhaou (S'97-M'02, SM'2011) as an Assistant Professor at Qassim University, Saudi Arabia and University of Monastir, Tunisia. He received master's degree in Electrical Engineering from the Tampere University of Technology, Tampere, Finland, and the PhD degree from the Royal Institute of Technology, Stockholm, Sweden, in 1997, and 2002, respectively. His research interests are in the areas of green data center, loT for smart grid, interconnect optimization, low-power circuit design, high-level power estimation, arithmetic for cryptosystems, Intelligent Transportation Systems, and VLSI for DSP and wireless systems. He has authored and co-authored more than 50 journals, book chapters, technical reports and conference papers in these areas. Dr. Ben Dhaou received the Best Paper Award from the 1997 Finnish Symposium on Signal Processing and a travel grant from the Ph.D. forum at DAC, Los Angeles in 2000. Since September 2014, Dr. Ben Dhaou has been serving as editor to the microelectronics journal, Elsevier. He was the Guest Editor for the special issue of on-chip signaling in deep-submicron technology, Journal of Analog Integrated Circuits and Signal Processing.

Aron Kondoro received his Master of Science degree in Information and Communication Systems Security from the Royal Institute of Technology (KTH - Sweden) in 2012 and Bachelor of Science in Computer Science from the University of Dar es Salaam in 2007. He is an Assistant Lecturer in the Computer Science and Engineering (CSE) Department at the University of Dar es Salaam (UDSM), Tanzania. Currently, he is a PhD student at KTH/UDSM doing research in using smart grid technologies to design and implement more efficient, reliable and autonomous solar-driven microgrids for off-grid rural communities. His other research and consultancy activities are focused on analyzing ICT systems security and using mobile technologies to design applications for educational and financial use-cases.

Anastasia Anagnostou is Research Fellow at the Department of Computer Science, Brunel University London. She holds a PhD in Hybrid Distributed Simulation, an MSc in Telemedicine and e-Health Systems and a BSc in Electronics Engineering. Her research interests are related to the application of modeling and simulation techniques in the Healthcare and Industry. Her ORCID is orcid.org/0000-0003-3397-8307.

Amleset Kelati, senior researcher, is a Research Engineer for SIDA funded iGrid Project and MIC project financed by a grant from STINT (The Swedish Foundation for International Cooperation in Research and Higher Education) at the Department of Electronics, School of Computer Science and Electrical Engineering, Royal Institute of Technology (KTH), Sweden (July 2016 until present). She obtained her MSc degree in Electronics Engineering from the Universidad Central de las villas, Santa Clara, in 1986, MSc degree in Electrical Engineering, specialization System on chip Design from Royal Institute of Technology (KTH), Sweden in 2004 and MSc degree in Communication Engineering and specialization Digital Communication Systems Technology from Chalmers University of Technology, Gothenburg, in 2015. She has been Visiting Researcher at Department Electronics System in the Royal Institute of Technology (Oct. 2013 - June. 2016). She is currently a PhD student at the Department of Future Technologies, Faculty of Science and Engineering, University of Turku and member of the Internet-of-Things for Healthcare (loT4Health) Group (April 2014 until now). She has more than 17 years'industry work experience by holding positions at Ericsson, Zarlink, NXP, U-Blox with experience from digital design, design verification (functional verification) and validation (lab evaluation) of ultra-low power RF transceivers. She has research experience in adaptive and self-aware embedded systems design, sensor networks, internet-of-things, security for wireless communication system, security aware design for on ultra-low power RFIC design, low-power integrated circuits, wireless sensing and DSP, Embedded system feature extraction method. She has reviewed more than 20 publications and has published 17 publications for conferences and journals. Amleset is a Senior member IEEE.

Shililiandumi Naiman is a holder of a Bachelor of Science degree in Electrical Engineering (BSc EE) (2001), Master of Science degree in Telecommunication Engineering (2004), and a PhD degree in Telecommunication Engineering (2015) from the University of Dar es Salaam, Tanzania. His PhD study was majoring in power-line communication. Currently he is working in the Department of Electronic and Telecommunication Engineering, College of Information and Communication Technologies (CoICT), University of Dar-es-Salaam as a Lecturer. He is a Registered Professional Engineer in Tanzania by Engineer Registration Board (ERB). His main research interests include power-line communication, Smart grid, microwave communications, antenna, fiber-optic communication, multimedia communication, digital electronics and signal processing. Between 2016 and 2017, he has been a Post-Doctoral Research Fellow at the iGrid-Project funded by Sida and hosted by two universities KTH and UDSM. Currently he is a member of iGrid-Project groupof University of Dar es salaam. 
Simon J. E. Taylor is the leader of the Modelling \& Simulation Research Group in the Department of Computer Science, Brunel University London (https://tinyurl.com/ya5zjh8z). He leads major projects in industry and Africa. He a member of the ACM SIGSIM Steering Committee and founder of the Journal of Simulation. He has chaired several major conferences and his published over 150 articles.

Nerey Mvungi received a BSc in electrical engineering from the University Dare es Salaam, Dare es Salaam, Tanzania, in 1978. He received the M.Sc degree in electronics control from Salford University, Salford, UK in 1980 and PhD degree from Leeds University Leeds, UK in 1989. He was with Phillips Center for Technology in Eindhoven, Eindhoven, Netherlands in 1982/83. He has been with the University of Dar es Salaam from April 1978 until September 2008 in various academic and administrative capacities. He has done a number of research and consultancy projects and specialized professional services in Tanzania and beyond. He served in a number of committees outside the University of Dodoma and the University of Dar es Salaam. He is Professor at the College of ICT of the University of Dar es Salaam and founding Principal. He was a Professor and founding Principal of the College of Informatics and Virtual Education of the University of Dodoma. His research interest is in control and instrumentation, computer communication and applied electronics, lightning protection, rural access, power quality aspects, and remote monitoring and control of energy consumption. He is a Consulting Engineer in Tanzania (CEng), member IET(TZ), AMSTS, Member ICAE. He received the 2010 IBM Faculty Award, TCRA 2013 Award, 2015-2020 Sida Award, PI for Overall Winner of the 2016 UDSM Research Week.

Hannu Tenhunen received the Diploma Engineer degree in electrical engineering and computer sciences from Helsinki University of Technology, Helsinki, Finland, in 1982 and PhD degree in microelectronics from Cornell University, Ithaca, NY, in 1986. During 1978-1982, he was with Electron Physics Laboratory, Helsinki University of Technology. From 1983 to 1985, he was with Cornell University as a Fulbright Scholar. From September 1985, he was with the Signal Processing Laboratory, Tampere University of Technology, Finland, as an Associate Professor. He was also a Coordinator of the National Microelectronics Program of Finland during 1987-1991. Since January 1992, he has been with Royal Institute of Technology, Sweden, where he is a Chair Professor in electronic system design. He has honorary doctorate and honorary professor degrees and have received a Mangolian Silver Award and Metal from city of Shanghai for his contributions there. His current research interests are VLSI circuits and systems for autonomic and smart systems and IOT. He has been actively involved in several EU programs on VLSI/ system-on-a-chip. He was education director of European Institute of Innovation and Technology EIT Digital. He has published over 815 reviewed publications and holds 9 international patents. 